\title{
Nebulized PPAR agonists: a novel approach to augment neonatal lung maturation and injury repair in rats
}

\author{
Edith Morales ${ }^{1,2}$, Reiko Sakurai', Sumair Husain', Dave Paek', Ming Gong' ${ }^{1}$, Basil Ibe' ${ }^{1}$ Yishi Li ${ }^{1}$, Maleha Husain', John S. Torday' \\ and Virender K. Rehan'
}

\begin{abstract}
BACKGROUND: By stimulating lipofibroblast maturation, parenterally administered peroxisome proliferator-activated receptor $\gamma$ (PPAR $\gamma$ ) agonists promote lung homeostasis and injury repair in the neonatal lung. In this study, we determined whether PPAR $\gamma$ agonists could be delivered effectively via nebulization to neonates, and whether this approach would also protect against hyperoxia-induced lung injury.
\end{abstract}

METHODS: One-day old Sprague-Dawley rat pups were administered PPAR $\gamma$ agonists rosiglitazone (RGZ, $3 \mathrm{mg} / \mathrm{kg}$ ), pioglitazone $(P G Z, 3 \mathrm{mg} / \mathrm{kg}$ ), or the diluent, via nebulization every $24 \mathrm{~h}$; animals were exposed to $21 \%$ or $95 \% \mathrm{O}_{2}$ for up to $72 \mathrm{~h}$. Twenty-four and $72 \mathrm{~h}$ following initial nebulization, the pups were sacrificed for lung tissue and blood collection to determine markers of lung maturation, injury repair, and RGZ and PGZ plasma levels.

RESULTS: Nebulized RGZ and PGZ enhanced lung maturation in both males and females, as evidenced by the increased expression of markers of alveolar epithelial and mesenchymal maturation. This approach also protected against hyperoxiainduced lung injury, since hyperoxia-induced changes in bronchoalveolar lavage cell and protein contents and lung injury markers were all blocked by nebulized PGZ.

CONCLUSION: Nebulized PPAR $\gamma$ agonist administration promotes lung maturation and prevents neonatal hyperoxiainduced lung injury in both males and females.

D espite several technological and therapeutic advances over the last two or three decades, bronchopulmonary dysplasia remains a significant cause of morbidity in very low birth weight infants. Bronchopulmonary dysplasia is characterized by aberrations in premature lung development following exposure to conditions such as hyperoxia, volutrauma, inflammation, and/or atelectotrauma, resulting in significantly increased prematurity-related morbidity and mortality. Therefore, attempts to advance lung maturity and develop lung-protective strategies have been the focus of research for many decades.

By stimulating alveolar interstitial lipofibroblast maturation, the nuclear transcription factor peroxisome proliferator-activated receptor $\gamma(\mathrm{PPAR} \gamma)$ has been demonstrated to play a key role in physiologic lung development and homeostasis (1-3). Lipofibroblasts have been demonstrated to play a central role in normal lung development by inducing alveolar epithelial-mesenchymal paracrine signaling, stimulating surfactant phospholipid and protein synthesis and by acting as endogenous antioxidants $(1,2,4)$. This is important since antenatal steroid administration, the contemporary standard intervention for enhancing fetal lung maturation, has significant limitations. For example, this therapy is effective in only $50-70 \%$ of infants, is sex-specific, has a delayed onset of action, and with repeated use, it may result in significant somatic growth restriction and neurodevelopmental handicaps (5-8). In view of the limited options for agents that can be used to stimulate lung maturation, alternate strategies for accelerating fetal lung maturation that are effective and safe are needed.

We have previously shown that the systemic administration of the PPAR $\gamma$ agonist rosiglitazone (RGZ), either antenatally or postnatally, enhances lung maturation and can prevent hyperoxia-induced acute neonatal lung injury without significantly affecting blood biochemical and metabolic profiles, both in the short and long terms, suggesting the therapeutic usefulness of PPAR $\gamma$ agonists in preventing and/or treating bronchopulmonary dysplasia $(3,9-13)$. However, in adults, systemically administered PPAR $\gamma$ agonists are known to be associated with significant side effects (14-16). Here, we determined whether PPAR $\gamma$ agonists could be delivered effectively via nebulization, and whether this would afford protection against hyperoxiainduced neonatal lung injury. Though we have previously used RGZ to study the effects of the PPAR $\gamma$ agonist class of agents on lung maturation, in this study, we also included pioglitazone (PGZ) because of its superior safety profile in adults when compared to RGZ $(17,18)$. Hypothesizing that PPAR $\gamma$ agonists given via nebulization would enhance lung maturation and block hyperoxia-induced lung injury, using a rat model, in this study, we determined whether the nebulized PPAR $\gamma$ agonists RGZ or PGZ stimulate lung maturation, protect against hyperoxia-induced acute neonatal lung injury, and affect extra-pulmonary PPAR $\gamma$-expressing organs. Lung maturation was assessed by determining the expression of key alveolar epithelial and mesenchymal molecular markers that are the hallmarks for the functional maturation of the developing

'Department of Pediatrics, Harbor-University of California Los Angeles (UCLA) Medical Center, Los Angeles Biomedical Research Institute, David Geffen School of Medicine at UCLA, Torrance, California; ${ }^{2}$ Department of Pediatrics, Children's Hospital Orange County, Orange, California. Correspondence: Virender K. Rehan (vrehan@labiomed.org) 


\section{Articles $\mid$ Morales et al.}

a

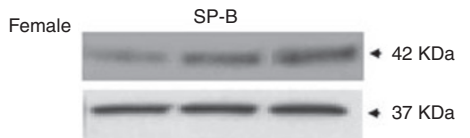

SP-C

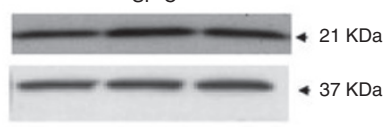

SP-B

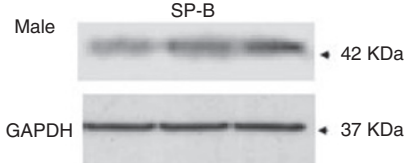

SP-C

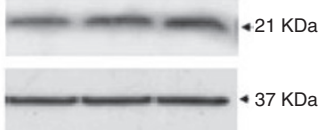

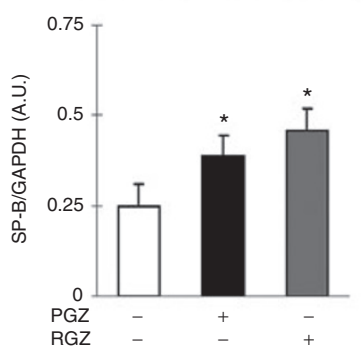
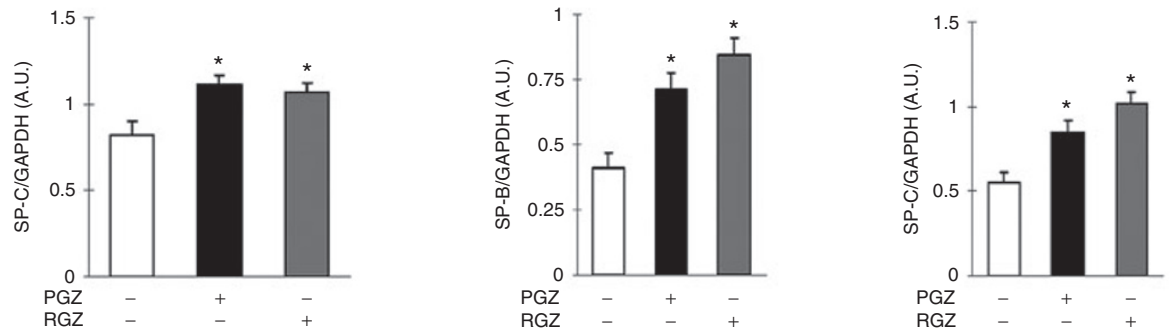

b
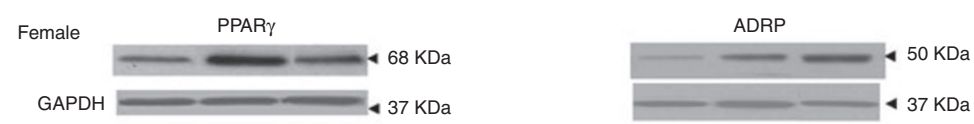

Leptin
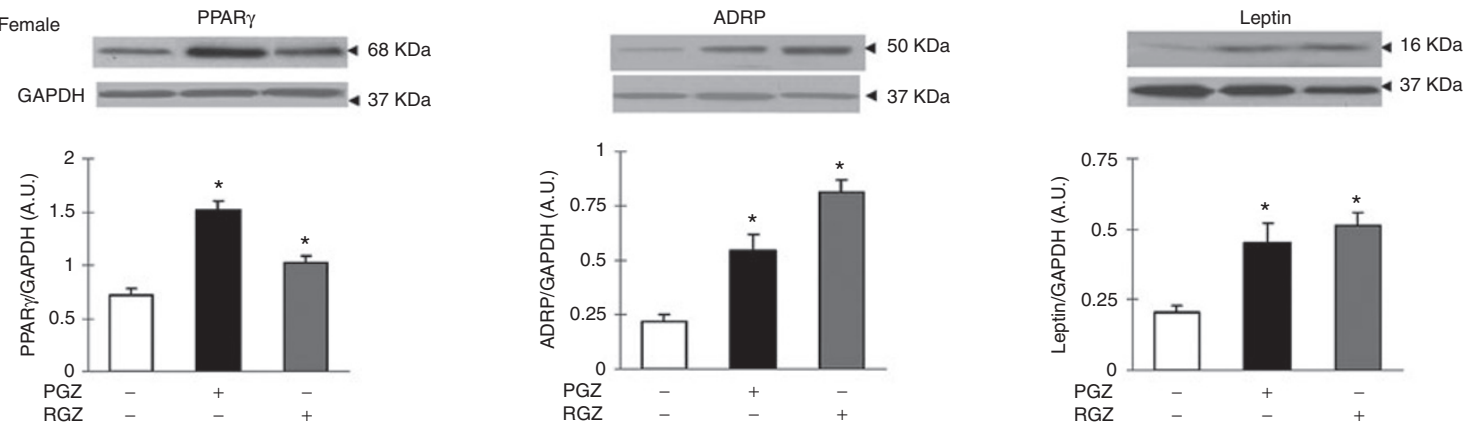

Male
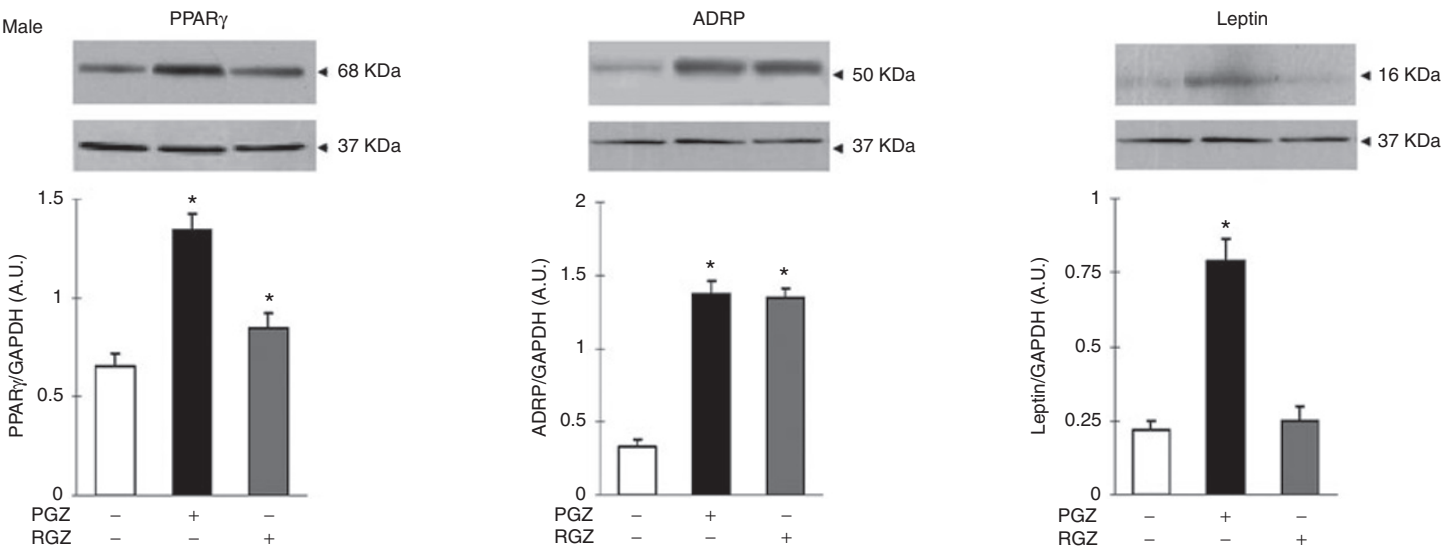

c
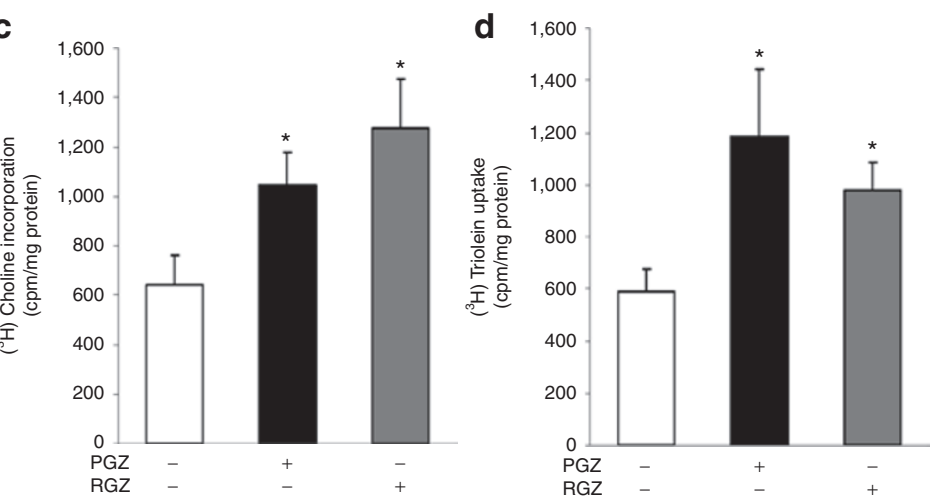

Figure 1. Effects of nebulized rosiglitazone (RGZ) or pioglitazone (PGZ) on alveolar epithelial and mesenchymal differentiation markers in the female and male rat pup lung. (a) Twenty-four hours following either RGZ or PGZ nebulization resulted in increased expression of SP-B and SP-C in both females and males. Similarly, (b) either PGZ or RGZ stimulated the alveolar mesenchymal differentiation markers peroxisome proliferator-activated receptor $\gamma$ (PPAR $\gamma$ ), adipocyte differentiation-related protein (ADRP), and leptin in both females and males; $n=4 ;{ }^{*} P<0.05$, control vs. treated animals. Either nebulized RGZ or PGZ also increased $(\mathbf{c})\left[{ }^{3} \mathrm{H}\right]$ choline incorporation and (d) triolein uptake; $n=6 ;{ }^{*} P<0.05$, control vs. treated animals. White bars, controls; black bars, PGZ group; and gray bars, RGZ group. A.U., arbitrary units; GAPDH, glyceraldehyde-3-phosphate dehydrogenase. 
lung, including expression of surfactant proteins (SPs) B and C, choline incorporation into saturated phosphatidylcholine, and triolein uptake by the lung. To assess lung injury, in addition to these markers of lung maturation, lung morphometry, lung apoptosis, important intermediates of transforming growth factor $\beta$ (TGF- $\beta$ ) activation and lung vascular markers (vascular endothelial-derived growth factor and platelet endothelial cell adhesion molecule-1), lung cytokines (IL-6, IL-1 $\beta$, chemokine ligand 2, and macrophage migration inhibitory factor), and bronchoalveolar lavage (BAL) fluid protein and cellular contents were analyzed.

As proof-of-principle for possible systemic effects of nebulized PPAR $\gamma$, plasma levels of RGZ and PGZ, and PPAR $\gamma$ receptor expression in liver, heart, and kidney were determined (PPAR $\gamma$ is expressed in a wide range of tissues such as, but not limited to, adipose tissue, heart, brain, skeletal muscle, liver, intestine, kidney, pancreas, and spleen).

\section{RESULTS}

\section{Effect of Nebulized RGZ and PGZ on Alveolar Differentiation Markers}

Twenty-four hours following nebulization, compared to the controls, RGZ and PGZ increased the expression of lung epithelial differentiation markers (SPB and SPC) in both females and males (Figure 1a), though there were no differences in response between the two genders. Since our laboratory has previously shown that mesenchymal PPAR $\gamma$ signaling is key to alveolar differentiation, we determined the effects of nebulized
PGZ and RGZ on PPAR $\gamma$ and its down-stream targets adipocyte differentiation-related protein (ADRP) and leptin. Twenty-four hours following nebulization, the expression of these markers was significantly increased in both females (PPAR $\gamma$, ADRP, and leptin, with both PGZ and RGZ), and males (PPAR $\gamma$, ADRP, and leptin with PGZ, and PPAR $\gamma$ and ADRP with RGZ) (Figure 1b). The effects of nebulized PGZ and RGZ on overall alveolar maturation are also reflected by functional alveolar markers such as a significantly increased rate of $\left[{ }^{3} \mathrm{H}\right]$ choline incorporation into saturated phosphatidylcholine (Figure 1c), and increased rates of triolein uptake (Figure 1d) in response to both PGZ and RGZ.

\section{Gender-Specific Effects of RGZ and PGZ Nebulization on Markers of Alveolar Maturation}

At the $24 \mathrm{~h}$ time point, there were no major differences in increases in epithelial (Figure 2a) and mesenchymal (Figure 2b) markers of alveolar maturation in males vs. females following exposure to nebulized RGZ or PGZ. Similarly, there were no significant differences in male and female responses for the markers of overall alveolar maturation; hence, the combined gender data for $\left[{ }^{3} \mathrm{H}\right]$ choline incorporation into saturated phosphatidylcholine and $\left[{ }^{3} \mathrm{H}\right]$ triolein uptake are shown in Figure 1c,d.

\section{Plasma Levels of RGZ and PGZ Following Nebulization}

Pioglitazone $(0.83 \pm 0.26 \mathrm{mg} / \mathrm{ml}$ (males); $0.99 \pm 0.21$ (females)) and RGZ (0.2 \pm 0.075 (male); $0.4 \pm 0.08 \mathrm{mg} / \mathrm{ml}$ (female)) were
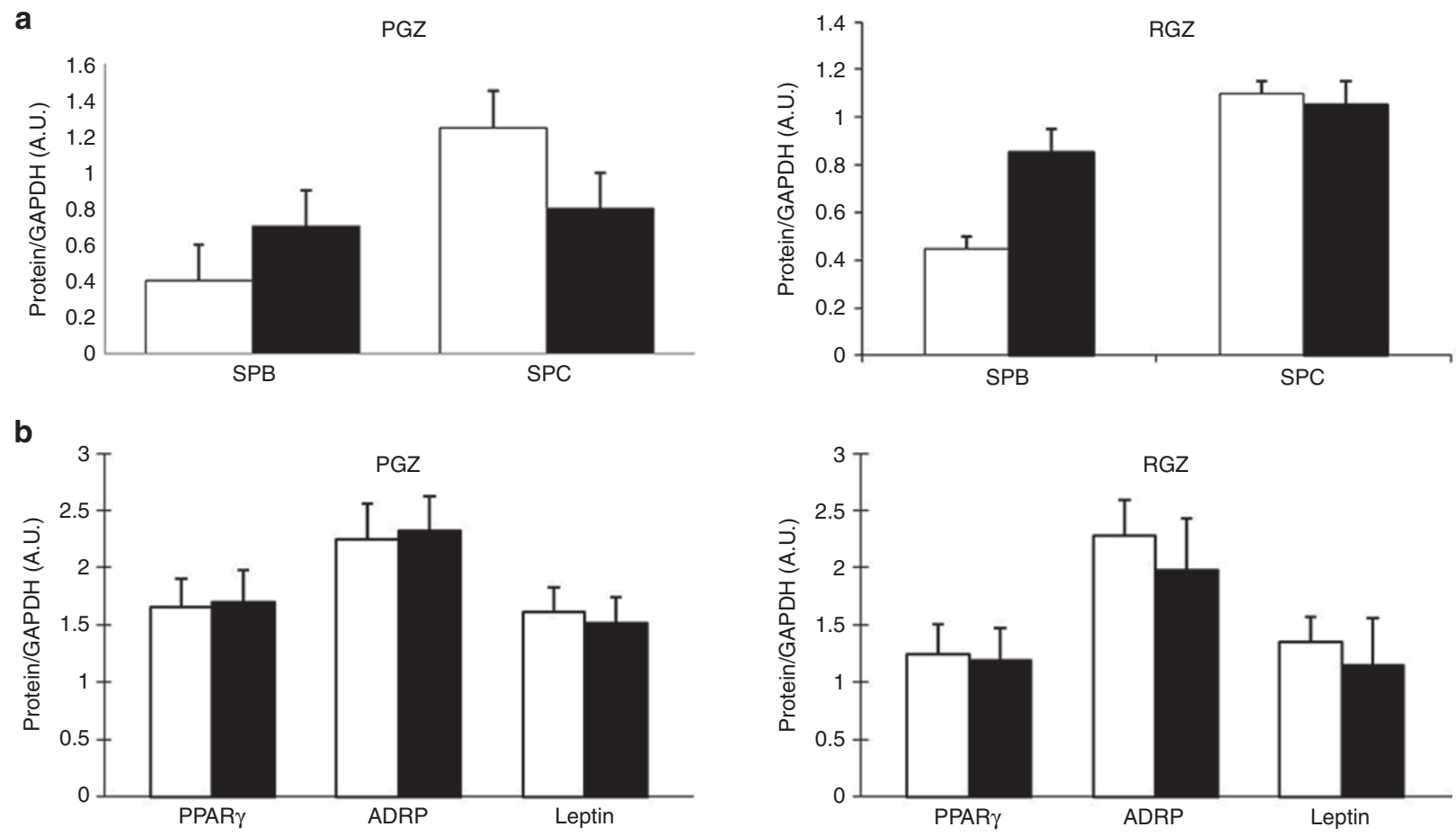

Figure 2. Comparative effects of nebulized rosiglitazone (RGZ) or pioglitazone (PGZ) on the expression of alveolar epithelial and mesenchymal differentiation markers in the female and male neonatal rat pup. There were no significant differences in the lung protein levels of (a) epithelial SPB and SPC and (b) mesenchymal, peroxisome proliferator-activated receptor $\gamma$ (PPAR $\gamma$ ), adipocyte differentiation-related protein (ADRP), and leptin, differentiation markers in the female (white bars) and male (black bars) newborn rat pup, $24 \mathrm{~h}$ following nebulized RGZ or PGZ ( $n=4 ; P>0.05$, control vs. treated animals). A.U., arbitrary units; GAPDH, glyceraldehyde-3-phosphate dehydrogenase. 
detectable in the plasma of males and females, $24 \mathrm{~h}$ after nebulization. Though female RGZ plasma levels were significantly higher than in males, there were no statistically significant differences in PGZ plasma levels between the males and females. At the $72 \mathrm{~h}$ time point, the plasma PGZ level for the combined gender group was $0.52 \pm 0.15 \mu \mathrm{g} / \mathrm{ml}$. As expected, PGZ and RGZ levels were undetectable in plasma samples from control groups.

\section{Effects of Nebulized RGZ and PGZ on Extrapulmonary PPAR $\gamma$ - Expressing Organs}

To assess the effects of nebulized RGZ and PGZ on extrapulmonary PPAR $\gamma$-expressing organs such as the liver, heart, and kidney, $24 \mathrm{~h}$ after nebulization, PPAR $\gamma$ protein levels in these tissues were determined. Only in the livers of the PGZ nebulized animals (both females and males) were the PPAR $\gamma$ protein levels significantly increased, while there were no significant effects on PPAR $\gamma$ protein levels in the hearts and kidneys of either the PGZ or RGZ nebulized animals (data not shown).

Having demonstrated that nebulized RGZ and PGZ administration enhanced neonatal rat lung maturation, we next examined whether nebulized PGZ provided any protection against hyperoxia-induced neonatal lung injury. For this, we administered nebulized PGZ once daily (q 24h), starting on day 1 of life, for up to $72 \mathrm{~h}$, and exposed the pups to either normoxia or hyperoxia $\left(95 \% \mathrm{O}_{2}\right)$ during the experimental period.

\section{Effects of Nebulized PGZ on Hyperoxia-Induced Neonatal Lung Injury}

Compared to the controls, the BAL total cell count (Figure 3a), macrophage count (Figure $3 \mathbf{b}$ ), and protein content (Figure 3c) after exposure to hyperoxia increased significantly, effects that were counteracted in the PGZ nebulized group. Examining markers of alveolar differentiation indicated significant decreases in triolein uptake (Figure 4a), PPAR $\gamma$ (Figure 4b), and ADRP (Figure 4c) protein levels, and significant increases in fibronectin (Figure 4d) protein levels in the hyperoxiaexposed group ( $P<0.05$ vs. control); all of these changes were blocked in the PGZ nebulized group. Hyperoxia-induced decreases in vascular markers such as vascular endothelialderived growth factor (Figure 5a) and platelet endothelial cell adhesion molecule-1 (Figure 5b) were blocked with PGZ nebulization. Similarly, hyperoxia-induced alterations in the lung cytokine (IL-6, IL-1 $\beta$, chemokine ligand 2, and macrophage migration inhibitory factor) profile were blocked in the PGZ nebulized group (Figure 6a-d). Hyperoxia-induced lung injury, as reflected by the decreased $\mathrm{BcL} 2 / \mathrm{Bax}$ protein ratio, was also blocked by PGZ nebulization (Figure 6e). In line with these data, and perhaps even more importantly, hyperoxiainduced lung morphometric changes, as determined by radial alveolar count and mean linear intercept, were also blocked in the PGZ nebulized group (Figure 7). To compare the efficacy of protection against hyperoxia-induced neonatal lung injury, using nebulized PGZ (1 mg/kg body weight) vs. that afforded by the intraperitoneally administered PGZ $(3 \mathrm{mg} / \mathrm{kg}$ body weight), alterations in select injury repair markers (PPAR $\gamma$, ADRP, BcL2, and fibronectin) were determined. There was
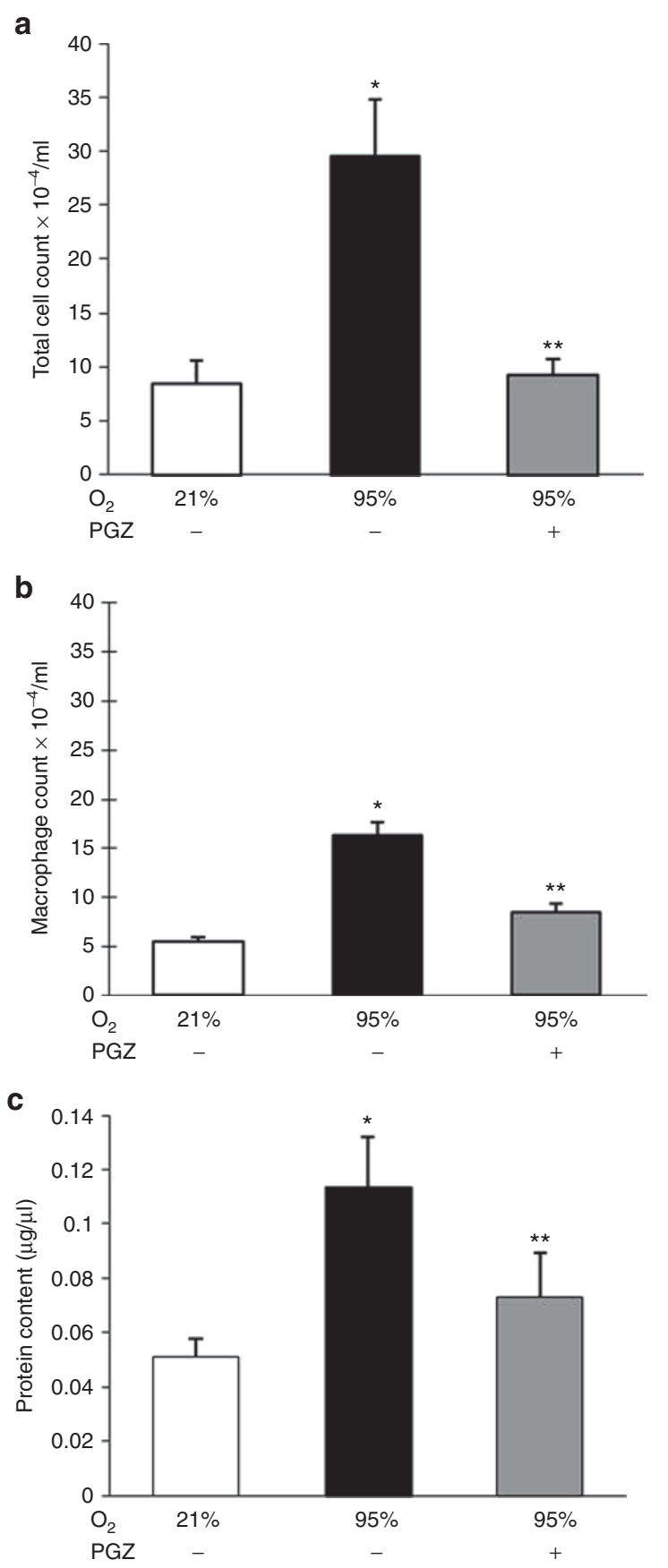

Figure 3. Effect of nebulized pioglitazone (PGZ) on total (a) bronchoalveolar lavage cell count, (b) macrophage count, and (c) total protein content after exposure of neonatal rat lung to hyperoxia $\left(95 \% \mathrm{O}_{2}\right)$ for $72 \mathrm{~h}$. When exposed to hyperoxia, the bronchoalveolar lavage total cell counts increased sixfold, and macrophage count and total protein content increased threefold each. In contrast, with nebulized PGZ, all of these BAL changes were blocked. White bars, $21 \% \mathrm{O}_{2}$; black bars, $95 \% \mathrm{O}_{2}$; and gray bars, $95 \% \mathrm{O}_{2}+\mathrm{PGZ} . n=4 ;{ }^{*} P<0.05$ vs. control; ${ }^{* * P}<0.05$ vs. $95 \% \mathrm{O}_{2}$.

equally effective protection in hyperoxia-induced alterations in these markers using the lower nebulized dose vs. the higher intraperitoneally administered dose (Figure 8).

Lastly, since hyperoxia-induced neonatal lung injury is known to be mediated via TGF- $\beta$ activation $(9,10)$, we next determined the effect of nebulized PGZ on hyperoxia-induced 
a

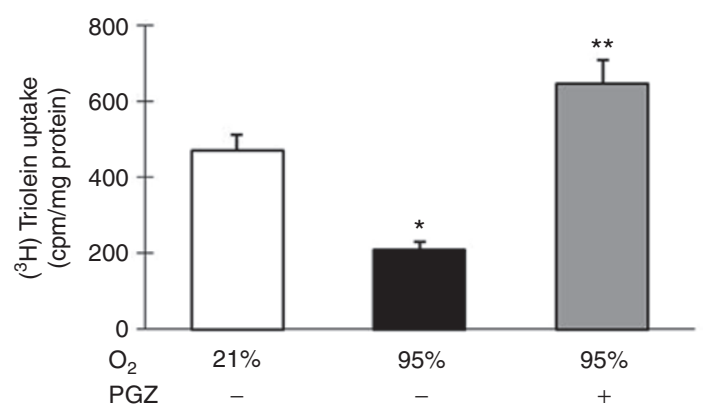

C
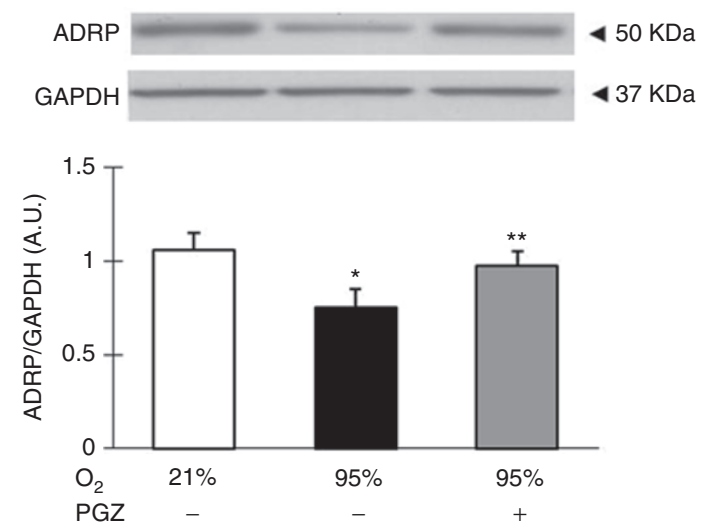

b
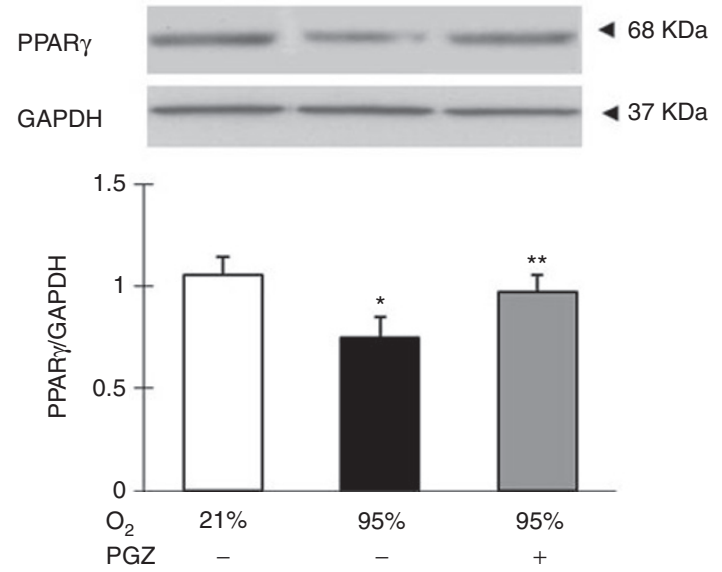

d
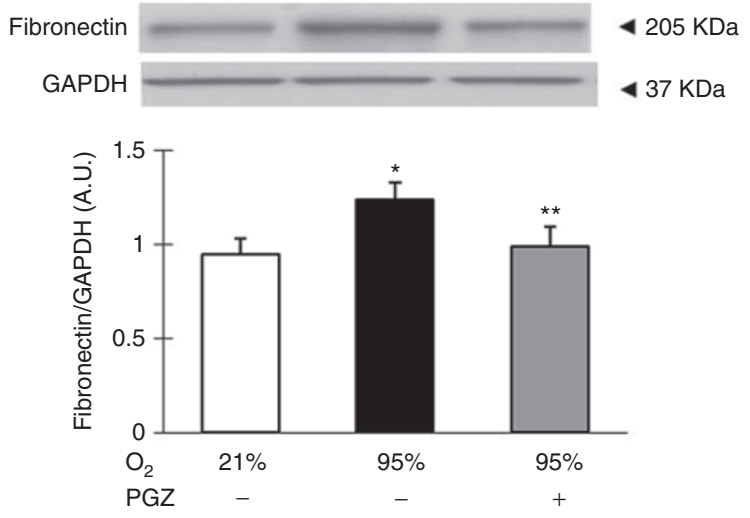

Figure 4. Effect of nebulized pioglitazone (PGZ) on neonatal rat lung triolein uptake and lung injury repair protein levels. When neonatal rat pups were exposed to hyperoxia for $72 \mathrm{~h}$, triolein uptake was diminished compared to controls. (a) In contrast, triolein uptake was clearly stimulated by treatment with nebulized PGZ after $72 \mathrm{~h}$ exposure to hyperoxia. Similarly, (b) peroxisome proliferator-activated receptor $\gamma($ PPAR $\gamma$ ) and (c) adipocyte differentiationrelated protein (ADRP) protein levels decreased and (d) fibronectin protein levels increased in the hyperoxia-exposed group $(P<0.05$ vs. control); all of these changes were blocked in the PGZ nebulized group. White bars, $21 \% \mathrm{O}_{2}$; black bars, $95 \% \mathrm{O}_{2}$; and gray bars, $95 \% \mathrm{O}_{2}+\mathrm{PGZ}(n=4$ for all; $* P<0.05$ vs. control; ${ }^{* * P}<0.05$ vs. $95 \% \mathrm{O}_{2}$ ). A.U., arbitrary units; GAPDH, glyceraldehyde-3-phosphate dehydrogenase.

a

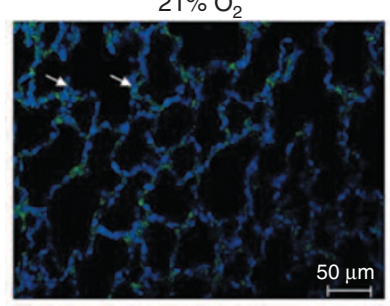

b

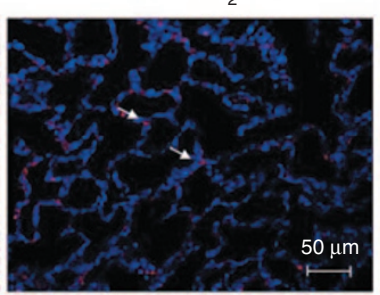

$95 \% \mathrm{O}_{2}$

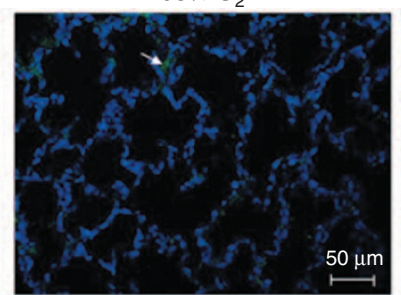

$95 \% \mathrm{O}_{2}$

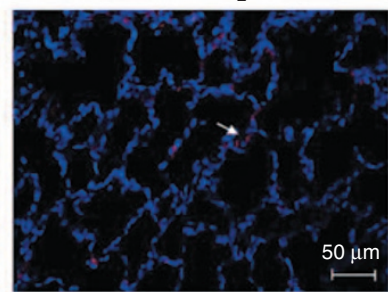

$95 \% \mathrm{O}_{2}+\mathrm{PGZ}$

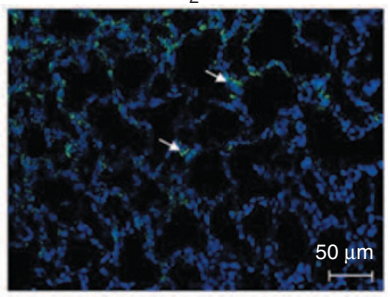

$95 \% \mathrm{O}_{2}+\mathrm{PGZ}$

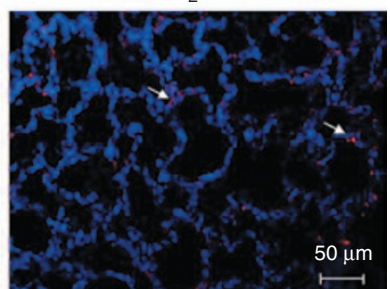

Figure 5. Effect of nebulized pioglitazone (PGZ) on hyperoxia-induced alterations in neonatal rat lung vascular markers vascular endothelial-derived growth factor (VEGF) and platelet endothelial cell adhesion molecule (PECAM)-1. As determined by immunostaining, $72 \mathrm{~h}$ hyperoxia-induced decreases in vascular markers (a) VEGF (upper panel, green fluorescence) and (b) PECAM-1 (lower panel, red fluorescence) were blocked with PGZ nebulization. White arrows show specific staining. 


\section{Articles $\mid$ Morales et al.}

a

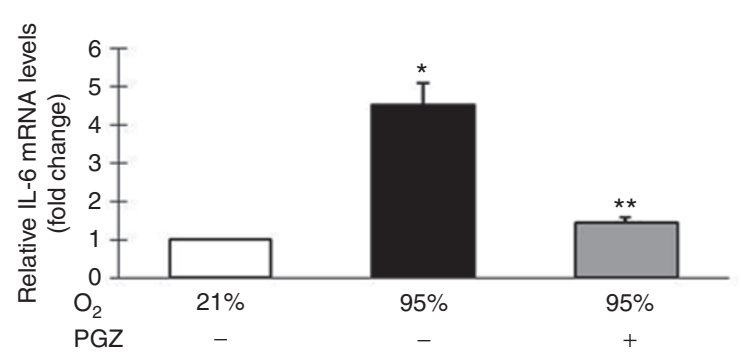

C

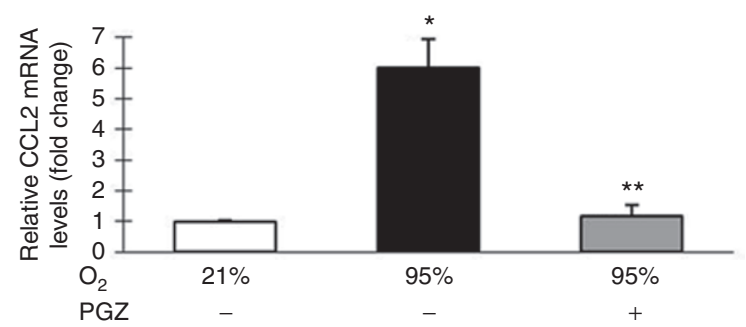

b

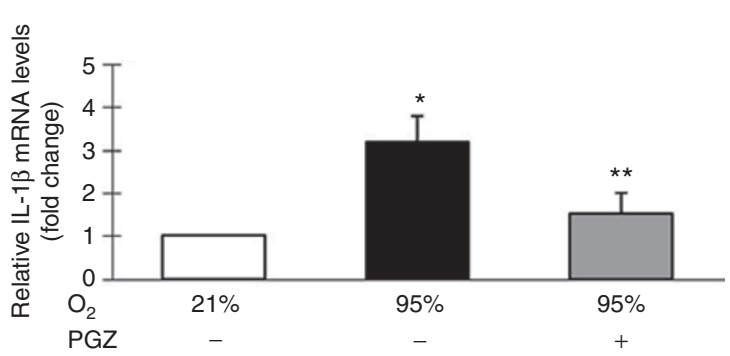

d

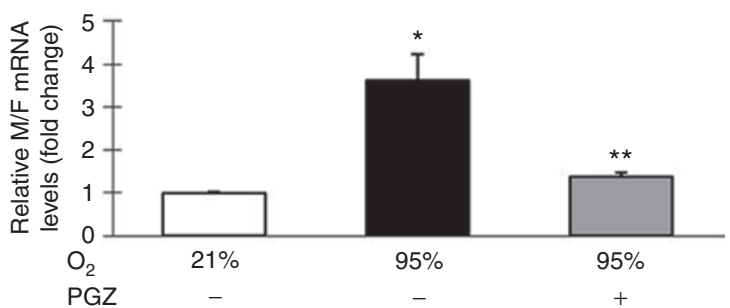

e
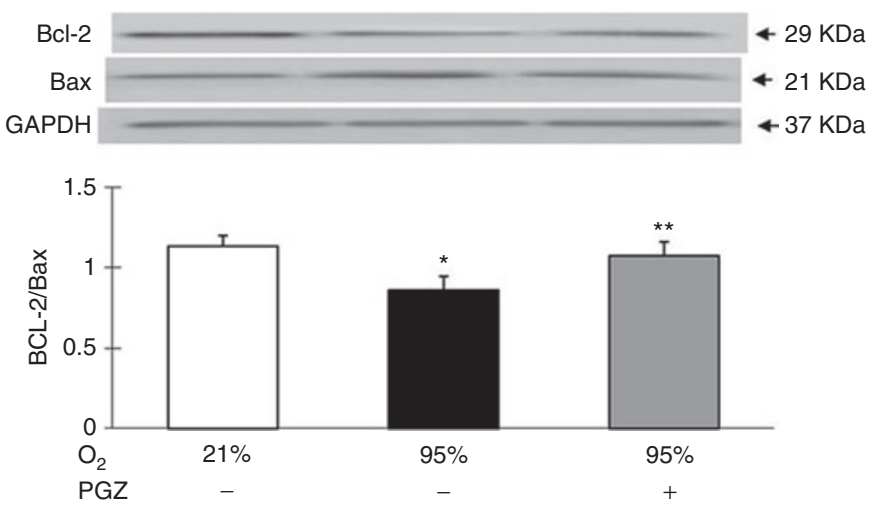

Figure 6. Effect of nebulized pioglitazone (PGZ) on hyperoxia-induced changes in neonatal rat lung inflammation-related cytokines and apoptosis (determined by BCL2/Bax protein ratio). Seventy-two hour hyperoxia exposure-induced alterations in lung cytokines, (a) IL-6, (b) IL-1 $\beta$, (c) chemokine ligand 2 (CCL-2), and (d) macrophage migration inhibitory factor (MIF), were blocked in the PGZ nebulized group, as was the decrease in (e) BCL2/Bax protein ratio. White bars, $21 \% \mathrm{O}_{2}$; black bars, $95 \% \mathrm{O}_{2}$; and gray bars, $95 \% \mathrm{O}_{2}+\mathrm{PGZ}\left(n=4\right.$ for all; $* P<0.05$ vs. control; ${ }^{* *} P<0.05$ vs. $95 \% \mathrm{O}_{2}$ ). GAPDH, glyceraldehyde-3-phosphate dehydrogenase.

alterations in key intermediates of TGF- $\beta$ activation. As expected, p-Smad3, Smad7, and ALK-5 (TGF- $\beta$ II receptor) protein levels were significantly increased in the hyperoxia exposure group, with blockade of this response in the PGZnebulized group (Figure 9).

\section{DISCUSSION}

In this study, we demonstrate that the PPAR $\gamma$ agonists RGZ and PGZ, given via nebulization to newborn Sprague Dawley rat pups result in enhanced lung maturation, in both male and female neonatal rat pups equally, as evidenced by the increased expression of alveolar epithelial (SPB, SPC, and surfactant phospholipid synthesis) and mesenchymal (PPAR $\gamma$, ADRP, and leptin protein levels, and triolein uptake) maturation markers. Furthermore, the nebulized PPAR $\gamma$ approach also protected against hyperoxia-induced neonatal lung injury, since hyperoxia-induced changes in BAL cell and protein contents, lung tissue maturation and injury markers (BcL2, Bax, and TGF- $\beta$ activation markers) were all blocked by nebulized
PGZ. In general the effects of nebulized RGZ or PGZ ( $3 \mathrm{mg} / \mathrm{kg}$ ) on alveolar mesenchymal and epithelial differentiation markers seem to be similar to the previously reported effects following intraperitoneal administration of RGZ at a comparable dose (3); however, at a lower dose ( $1 \mathrm{mg} / \mathrm{kg}$ body weight), nebulized PGZ, seems to be equally effective in preventing hyperoxia-induced neonatal lung injury compared to the protection afforded with a relatively higher parenterally-administered dose $(3 \mathrm{mg} / \mathrm{kg}$ body weight). Therefore, it seems that administration of nebulized PPAR $\gamma$ agonists represents an effective strategy for enhancing postnatal lung maturation, preventing neonatal hyperoxia-induced lung injury in both males and females.

Since, pulmonary immaturity is the main contributor to the morbidity and mortality of premature infants (19), it is of great relevance to determine novel and safer agents to stimulate lung maturation, acting in a nongender discriminatory manner. Other than antenatal steroids, no intervention has proven effective in enhancing lung maturation, let alone preventing 

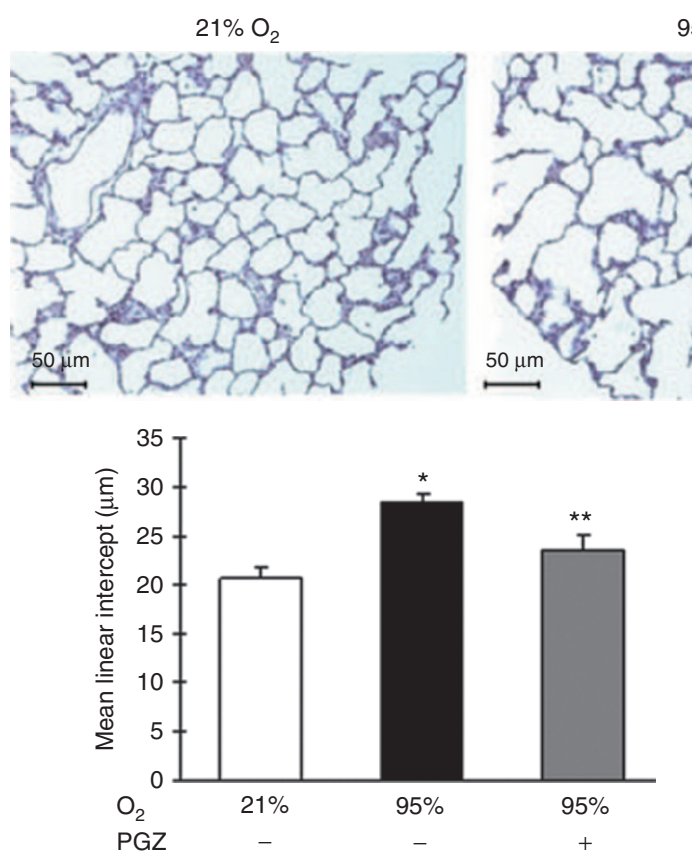

$95 \% \mathrm{O}_{2}$
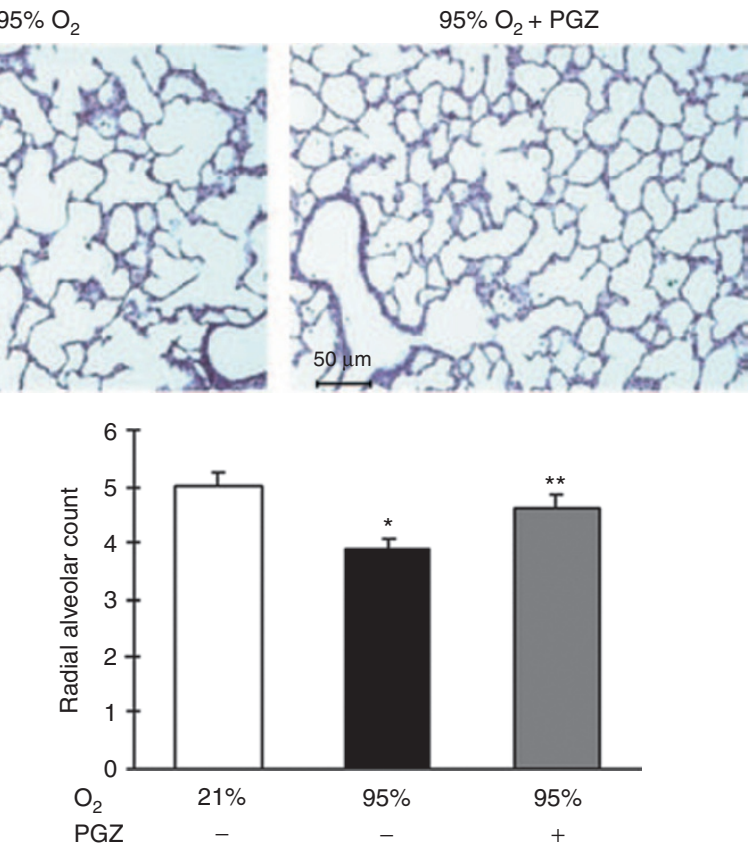

Figure 7. Effect of nebulized pioglitazone (PGZ) on hyperoxia-induced changes in lung morphometry. Seventy-two hour hyperoxia exposure-induced lung morphometric changes, as determined by mean linear intercept and radial alveolar count, were blocked in the PGZ nebulized group. White bars, $21 \% \mathrm{O}_{2} ;$ black bars, $95 \% \mathrm{O}_{2}$; and gray bars, $95 \% \mathrm{O}_{2}+\mathrm{PGZ}\left(n=4\right.$ for all; ${ }^{*} P<0.05$ vs. control; ${ }^{* *} P<0.05$ vs. $95 \% \mathrm{O}_{2} ;$ magnification $\left.=10 \times\right)$.

hyperoxia-induced lung damage $(5,20)$. A number of recent studies have suggested PPAR $\gamma$ agonists as potential lung maturation and protection agents (3,9-12,21-23). The prior work on the use of PPAR $\gamma$ agonists to enhance lung maturation has also shown that both antenatal and postnatal intraperitoneal RGZ administration block hyperoxia-induced lung molecular and morphometric changes postnatally $(9,10)$. Therefore, it should not be surprising that in line with the previous work, nebulized PGZ stimulated alveolar maturation and protection against hyperoxia-induced neonatal lung injury, since lipofibroblast differentiation is driven by PPAR $\gamma$, and since lipofibroblasts are known to be cytoprotective against oxidant injury, and produce specific growth and differentiation and homeostasis $(1,4,24)$. However, in adults the chronic use of PPAR $\gamma$ agonists has been shown to be associated with significant side effects, e.g., cardiovascular effects with RGZ, and bladder cancer with PGZ $(14-17,25)$. In line with our prior studies, where we have shown that RGZ given parenterally, either antenatally or postnatally, doesn't affect either cardiac troponin or any of the other metabolic parameters examined, such as the blood lipid profile and glucose and insulin tolerance tests $(3,11-13)$, in this study too, plasma cardiac troponin levels were undetectable in both control and hyperoxia-exposed animals with or without PGZ treatment.

We found that even when given via nebulization, both RGZ and PGZ seem to be systemically absorbed, as reflected by detectable plasma levels. However, other than the increase in the PPAR $\gamma$ protein levels in the livers of PGZ and RGZ nebulized animals, there seem to be no effects on either PPAR $\gamma$ or its downstream targets, such as ADRP and leptin protein levels (data not shown), in any other PPAR $\gamma$-expressing extra-pulmonary organs such as the heart and kidney, by either RGZ or PGZ.

In summary, treatment with nebulized PPAR $\gamma$ agonist accelerated neonatal lung maturation and prevented hyperoxiainduced lung injury, representing an effective and potentially safe therapeutic strategy. Though more work needs to be done to establish the safety profile and effective clinical use in neonates, the work presented here provides further proof-ofprinciple for the beneficial effects of this class of drugs in the prevention and management of neonatal lung injury.

\section{METHODS}

\section{Animal Protocol}

Pathogen-free, time-mated Sprague-Dawley rat dams were obtained from Charles River Laboratories (Hollister, CA) at day 16 of gestation, acclimatized in humidity- and temperature-controlled rooms with 12-h light and dark cycles, and provided food and water ad libitum. On day 22 of pregnancy the dams delivered spontaneously. One-day-old rat pups breastfed ad libitum were used and were grouped into nebulizing groups (using a Lincare Nebulizer, PariRespiratory Equipment, Midlothian, VA) as follows: One set of pups was maintained in room air and exposed to either nebulized $1 \mathrm{ml}$ normal saline containing the diluent dimethyl sulfoxide (DMSO) (Sigma-Aldrich, St Louis, MO) $(60 \mu \mathrm{l})$ and another set exposed to nebulized RGZ (Cayman Chemicals, Ann Arbor, MI) or PGZ (Cayman Chemicals) $(3 \mathrm{mg} / \mathrm{kg}$ in $60 \mu \mathrm{l}$ DMSO, diluted in $1 \mathrm{ml}$ saline), nebulized over $30 \mathrm{~min}$, in an enclosed chamber $(28 \times 17 \times 12 \mathrm{~cm})$. Twenty-four hour later pups were sacrificed for tissue and blood collection. For assessing the protection against hyperoxia-induced neonatal lung injury by using nebulized PPAR $\gamma$ agonist administration, some control animals were maintained in room air and nebulized with $1 \mathrm{ml}$ normal saline (containing the diluent DMSO), while the hyperoxia $\left(95 \% \mathrm{O}_{2}\right)$ exposure group animals were treated with either $1 \mathrm{ml}$ nebulized saline (containing the diluent DMSO) or nebulized PGZ (3 mg/kg in $60 \mu \mathrm{l}$ DMSO, diluted in $1 \mathrm{ml}$ saline), respectively, every $24 \mathrm{~h}$ for up to $72 \mathrm{~h}$. Continuous $95 \%$ 
a
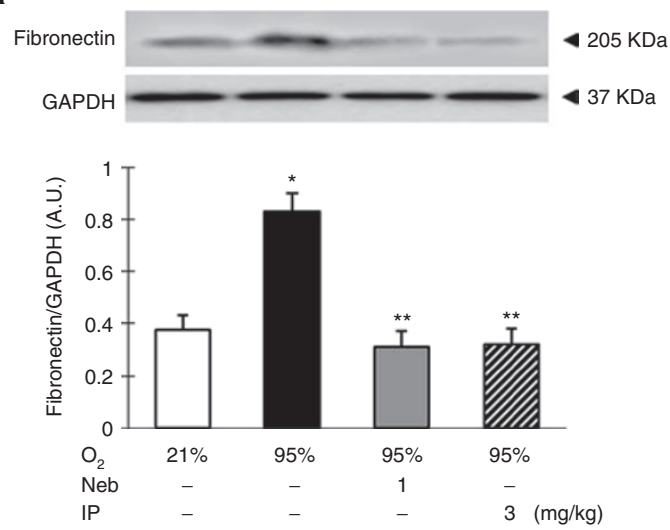

C
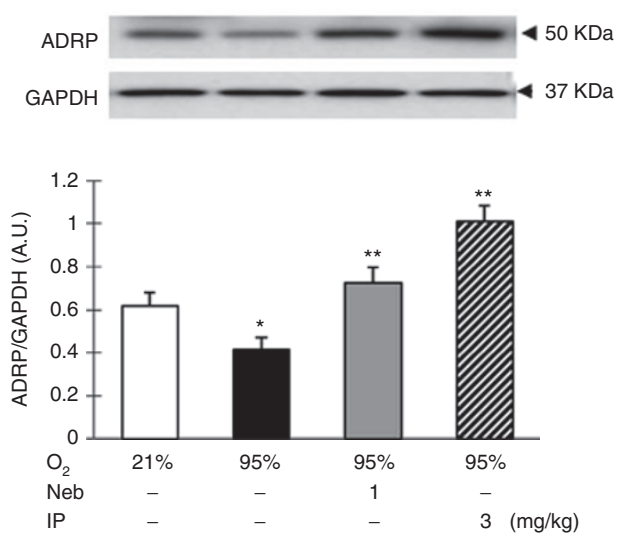

b
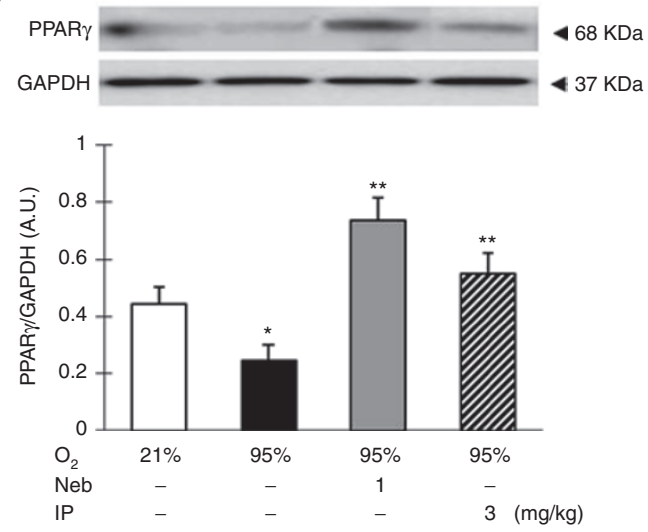

d
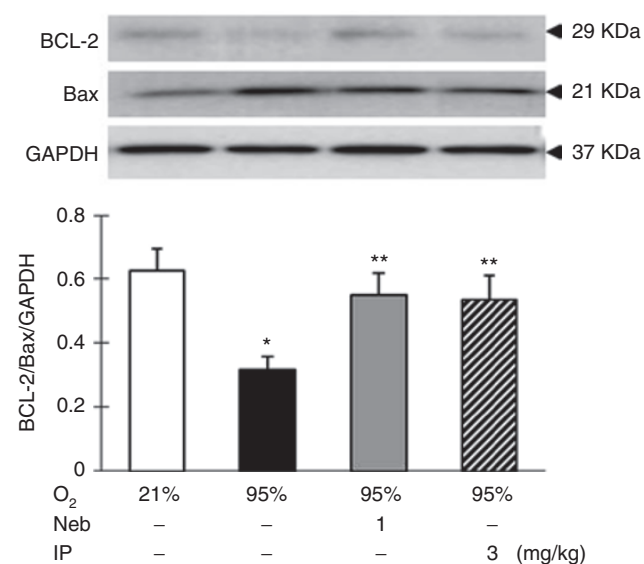

Figure 8. Comparison of the efficacy for protection against hyperoxia-induced lung injury using nebulized pioglitazone (PGZ) (1 mg/kg body weight) with that afforded by intraperitoneal PGZ ( $3 \mathrm{mg} / \mathrm{kg}$ body weight). Nebulized PGZ at a lower dose ( $1 \mathrm{mg} / \mathrm{kg} / \mathrm{body}$ weight) was equally effective in blocking hyperoxia induced decreases in (b) peroxisome proliferator-activated receptor $\gamma$ (PPAR $\gamma$ ), (c) adipocyte differentiation-related protein (ADRP), and (d) $B C L 2$, and increase in (a) fibronectin protein levels compared to that achieved by the higher intraperitoneally administered dose ( $3 \mathrm{mg} / \mathrm{kg}$ body weight). White bars, $21 \% \mathrm{O}_{2}$; black bars, $95 \% \mathrm{O}_{2}$; gray bars, $95 \% \mathrm{O}_{2}+$ nebulized PGZ; hatched bars, $95 \% \mathrm{O}_{2}+$ intraperitoneal PGZ. $N=3$ for all; * $P<0.05$ vs. control; ${ }^{* *} P<0.05$ vs. $95 \% \mathrm{O}_{2}$. A.U., arbitrary units; GAPDH, glyceraldehyde-3-phosphate dehydrogenase.

a

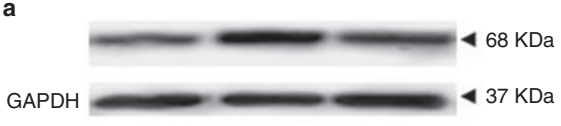

b

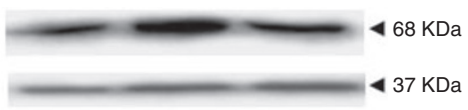

c

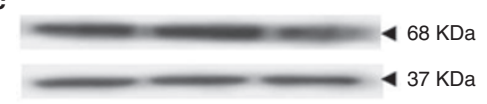

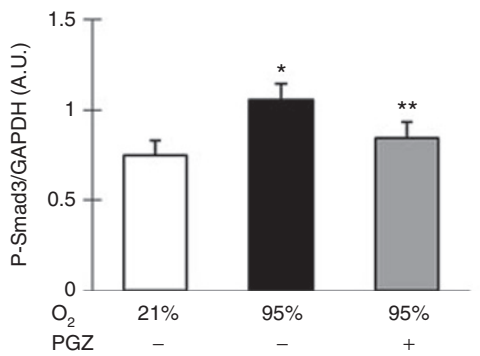
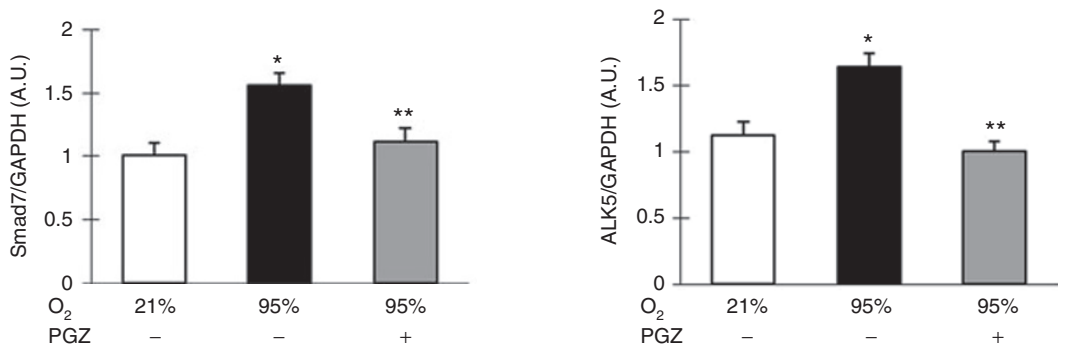

Figure 9. Effect of nebulized pioglitazone (PGZ) on hyperoxia-induced changes in key intermediates of TGF- $\beta$ activation. When newborn rat lung was exposed to $72 \mathrm{~h}$ hyperoxia, (a) P-Smad 3, (b) Smad 7, and (c) ALK 5 expression increased. In contrast, treatment with nebulized PGZ daily during the $72 \mathrm{~h}$ hyperoxia exposure prevented the stimulation of all of these TGF- $\beta$ activation markers. White bars, $21 \% \mathrm{O}_{2} ;$ black bars, $95 \% \mathrm{O}_{2} ;$ and gray bars, $95 \% \mathrm{O}_{2}+$ PGZ. $N=4 ;{ }^{*} P<0.05$ vs. control; ${ }^{*} P<0.05$ vs. $95 \% \mathrm{O}_{2}$. A.U., arbitrary units; GAPDH, glyceraldehyde-3-phosphate dehydrogenase.

$\mathrm{O}_{2}$ exposure was achieved in a plexiglass chamber $(77 \times 64 \times 37 \mathrm{~cm})$ using a flow-through system. For monitoring of oxygen levels inside the chamber, a Ceramatec $\left(\mathrm{MAXO}_{2}\right)$ oxygen analyzer (Maxtec, Salt Lake City, UT) was used. In yet another subset of animals, efficacy for protection against hyperoxia-induced lung injury using nebulized
PGZ (1 mg/kg body weight) administration was compared with the parenteral (intraperitoneal) PGZ $(3 \mathrm{mg} / \mathrm{kg}$ body weight) administration. After the experimental period, the pups were sacrificed using $0.1 \mathrm{ml}$ euthasol (sodium pentobarbital $390 \mathrm{mg}+$ sodium phenytoin $50 \mathrm{mg} / \mathrm{ml}$; Virbac, Fort Worth, TX) per pup. To determine the effects 
of RGZ or PGZ on extrapulmonary PPAR $\gamma$-expressing organs, heart, liver and kidney tissue was flash-frozen upon retrieval from the sacrificed animals. Blood was collected by cardiac puncture from each pup and frozen at $-80{ }^{\circ} \mathrm{C}$ for subsequent determination of plasma RGZ and PGZ levels. The lungs were collected and processed either immediately for $\left[{ }^{3} \mathrm{H}\right]$ choline incorporation and $\left[{ }^{3} \mathrm{H}\right]$ triolein uptake studies, or flash-frozen for later Western hybridization for the markers of lung maturation. All animal procedures were performed following the guidelines of the National Institutes of Health (Bethesda, $\mathrm{MD}$ ) for the care and use of laboratory animals, and approved by the Los Angeles Biomedical Research Institute, Animal Care and Use Committee.

\section{BAL Collection}

Pups were euthanized using pentobarbital ( $100 \mathrm{mg} / \mathrm{kg}$ i.p.), and a 27-gauge angiocatheter was ligated in place for BAL collection. Two $0.5-\mathrm{ml}$ BALs were slowly performed by instilling $0.5 \mathrm{ml}$ phosphatebuffered saline $+5 \mathrm{mmol} / \mathrm{l}$ ethylenediamine tetra-acetate. Retrieved solutions were pooled and centrifuged at $400 \mathrm{~g}$ for $10 \mathrm{~min}$. Sediments were analyzed for total cell counts and supernatants were snap-frozen in liquid nitrogen and subsequent analysis.

\section{Protein Extraction and Western Blot Analysis}

Liquid nitrogen flash-frozen lung tissue was homogenized with a tissue grinder in lysis buffer (RIPA buffer) containing $1 \mathrm{mmol} / \mathrm{l}$ ethylenediaminetetraacetic acid and ethylene glycol tetraacetic acid each (Boston Bioproducts, Ashland, MA), supplemented with $1 \mathrm{mmol} / \mathrm{l}$ phenylmethylsulfonyl fluoride, phosphate inhibitor (Sigma-Aldrich), and complete proteinase inhibitor cocktail (Roche Diagnostics, Indianapolis, IN). For each sample, fifty micrograms of total protein were denatured with SDS-PAGE sample buffer and electrophoresed in a $10 \%$ sodium dodecyl sulfate polyacrylamide gel. Resolved samples were then transferred onto a $0.45-\mu \mathrm{m}$ nitrocellulose or polyvinylidene difluoride membrane, which, after blocking with TBS-Tween (TBST) + 5\% milk, were probed with primary antibodies (PPAR $\gamma$ (1:500), ADRP (1:200), leptin (1:200), SPC (1:250), SPB (1:250), SMAD7 (1:150), ALK-5 (1:200), BcL-2 (1:350), Bax (1:600), fibronectin (1:250), all from Santa Cruz Biotechnology, (Santa Cruz, CA); P-SMAD3 (1:200) from Cell Signaling Technology, Danvers, MA); glyceraldehyde-3-phosphate dehydrogenase (1:10,000; MAb 374 (Chemicon, Temecula, CA)) overnight at $4{ }^{\circ} \mathrm{C}$, followed by appropriate secondary antibody and Super-Signal Chemiluminescent substrate (Pierce Chemicals, Rockford, IL). Photographic film (Denville Scientific, Metuchen, NJ) was used to quantitate protein bands, which were measured by densitometry using a scanning densitometer (Eagle Eye, Stratagene, La Jolla, CA) and expressed relative to accompanying glyceraldehyde-3-phosphate dehydrogenase bands as relative units.

\section{Measurement of Rate of Surfactant Phospholipid Synthesis}

De novo surfactant phospholipid synthesis, triglyceride uptake and incorporation of [methyl- $\left.{ }^{3} \mathrm{H}\right]$-choline chloride (NEN Dupont, Boston, MA) into saturated phosphatidylcholine in cultured lung explants were determined as described previously (13).

\section{Lung Morphometry}

Lung morphometry was performed as described previously $(3,10)$.

\section{Immunofluorescence Staining}

For immunofluorescence staining, rat lungs were inflated in situ with $4 \%$ paraformaldehyde in phosphate buffer at a standard inflation pressure of $5 \mathrm{~cm} \mathrm{H} \mathrm{H}_{2}$ for $4 \mathrm{~h}$ at $4{ }^{\circ} \mathrm{C}$. The lungs were subsequently transferred to phosphate-buffered saline containing $30 \%$ sucrose (wt/vol) until equilibrated in the cold $\left(4^{\circ} \mathrm{C}\right)$. After fixation, $5-\mu \mathrm{m}$ paraffin sections were treated three times with Histo-Clear (National Diagnostics, Atlanta, GA) for $5 \mathrm{~min}$, and then rehydrated by a sequential ethanol wash. Sections were then washed twice for $10 \mathrm{~min}$ with phosphatebuffered saline, and blocked for $1 \mathrm{~h}$ in phosphate-buffered saline-5\% normal goat serum- $0.2 \%$ Triton $\mathrm{X}-100$. Sections were incubated with primary antibodies for $1 \mathrm{~h}$ at room temperature, and then with the appropriate secondary antibody for $1 \mathrm{~h}$, also at room temperature. Antibodies used included platelet endothelial cell adhesion molecule (primary antibody, 1:10, BD Biosciences, San Jose, CA); secondary antibody, 1:100, Alexa Fluor, anti-rabbit 568 red); BCL-2 (primary antibody, 1:100, Santa Cruz, Santa Cruz, CA; secondary antibody, 1:100, Alexa Fluor, anti-rabbit 488 green); Bax (primary antibody, 1:100, Santa Cruz; secondary antibody, 1:100, Alexa Fluor, anti-rabbit $568 \mathrm{red})$. The sections were washed with phosphate buffered saline and then mounted with ProLong Gold antifade reagent with DAPI (Invitrogen) for visualization under a fluorescence microscope.

\section{Real Time RT-PCR}

For lung cytokine assay, RNA extraction and q-RT-PCR was performed according to previously described methods (26). RT-PCR primers used included IL6: F5'-CTTCCTACCCCAACTTCCAA-3' and R5'-ACCACAGTGAGGAATGTCCA-3' (191 bp); IL-1ß: F5'-AGA GTGTGGATCCCAAACAA-3' and R5'-AGTCAACTATGTCCCGA CCA-3' (186bp); chemokine ligand 2: F5'-TTGTCACCAAGCTCAA GAGA-3' and R5'-GGTTGTGGAAAAGAGAGTGG-3' (206bp); and macrophage migration inhibitory factor: F5'-AGAACCG CAACTACAGCAAG-3' andR 5'-ACGGGTGGATAAACACAGAA-3' (208 bp). The normalization control was 18S ribosomal RNA. Data were analyzed using a threshold level of fluorescence that was in the linear range of the PCR reaction. The CT value for $18 \mathrm{~S}$ ribosomal RNA was subtracted from the CT value for the gene of interest to obtain a delta $\mathrm{CT}(\Delta \mathrm{CT})$ value. The relative fold-change for each gene was calculated using the $\Delta \Delta C T$ method. Results were expressed as the mean $\pm \mathrm{SE}$, and considered statistically significant at $P<0.05$.

\section{Measurement of RGZ and PGZ in Plasma and Lungs}

RGZ and PGZ were measured by a high-performance liquid chromatography (HPLC) gradient program using a 50:50 (or 1:1) mixture of acetonitrile and methanol (solvent $\mathrm{A}$ ), and $50 \mathrm{mmol} / \mathrm{l}$ ammonium acetate buffer, pH 8.0 (solvent B). The HPLC column was a Whatman mBondapak $\mathrm{C}_{18}$ analytic column $(3.6 \times 150 \mathrm{~mm})$. Elution of RGZ and PGZ was accomplished with a timed gradient program beginning with $100 \%$ solvent $\mathrm{B}, 5 \mathrm{~min}$; then changed to $50 \%$ solvent $\mathrm{B}$ for $20 \mathrm{~min}$; followed by $95 \%$ solvent B for $5 \mathrm{~min}$ and held for $10 \mathrm{~min}$ at this percentage of $95 \%$ solvent $\mathrm{B}$. RGZ and PGZ had retention times of $29 \pm 0.5 \mathrm{~min}$, and $15 \pm 0.5 \mathrm{~min}$, respectively, and the amounts of RGZ and PGZ were calculated from a standard curve for pure RGZ run in tandem for each assay.

\section{Measurement of Plasma Cardiac Troponin I Levels}

Plasma cardiac troponin I levels were determined by a rat cardiac Tn-I ELISA kit as per the manufacturer's protocol (Life Diagnostics, West Chester, PA) (detection limit of $0.156 \mathrm{ng} / \mathrm{ml}$, and $100 \%$ specificity).

\section{Statistical Analysis}

The experiments were done at least three independent times. The experimental data was analyzed using one-way analysis of variance, with Tukey's post hoc analysis as appropriate. The results are expressed as means \pm SD. $P$ value of $<0.05$ was considered to represent statistically significant differences between the groups.

\section{STATEMENT OF FINANCIAL SUPPORT}

National Institutes of Health (Bethesda, MD) grants HL075405, HL55268, HD51857, HD058948, HL107118, and HD071731. E.M. was in part supported by a grant from Children's Hospital of Orange County.

Disclosure: The authors declare no conflict of interest.

\section{REFERENCES}

1. Torday JS, Torres E, Rehan VK. The role of fibroblast transdifferentiation in lung epithelial cell proliferation, differentiation, and repair in vitro. Pediatr Pathol Mol Med 2003;22:189-207.

2. Simon DM, Arikan MC, Srisuma S, et al. Epithelial cell PPAR[gamma] contributes to normal lung maturation. FASEB J 2006;20:1507-9.

3. Wang Y, Santos J, Sakurai R, et al. Peroxisome proliferator-activated receptor gamma agonists enhance lung maturation in a neonatal rat model. Pediatr Res 2009;65:150-5.

4. Torday JS, Torday DP, Gutnick J, Qin J, Rehan V. Biologic role of fetal lung fibroblast triglycerides as antioxidants. Pediatr Res 2001;49:843-9.

5. NIH Consensus Development Panel on the Effect of Corticosteroids for Fetal Maturation on Perinatal Outcomes. Effect of corticosteroids for fetal maturation on perinatal outcomes. JAMA 1995; 273:413-8. 
6. Wapner RJ, Sorokin Y, Mele L, et al.; National Institute of Child Health and Human Development Maternal-Fetal Medicine Units Network. Long-term outcomes after repeat doses of antenatal corticosteroids. N Engl J Med 2007;357:1190-8

7. Ballard PL, Ballard RA, Granberg JP, et al. Fetal sex and prenatal betamethasone therapy. J Pediatr 1980;97:451-4.

8. Nielsen HC, Torday JS. Sex differences in fetal lung development: Biology, etiology, and evolutionary significance. In: Mendelson CR, ed. Endocrinology of the Lung-Development and Surfactant Synthesis. Totowa, NJ: Humana Press, 2000:141-59.

9. Rehan VK, Sakurai R, Corral J, et al. Antenatally administered PPARgamma agonist rosiglitazone prevents hyperoxia-induced neonatal rat lung injury. Am J Physiol Lung Cell Mol Physiol 2010;299:L672-80.

10. Dasgupta C, Sakurai R, Wang Y, et al. Hyperoxia-induced neonatal rat lung injury involves activation of TGF- $\{$ beta $\}$ and Wnt signaling and is protected by rosiglitazone. Am J Physiol Lung Cell Mol Physiol 2009;296: L1031-41.

11. Truong NC, Abbasi A, Sakurai R, Lee WN, Torday JS, Rehan VK. Postnatal rosiglitazone administration to neonatal rat pups does not alter the young adult metabolic phenotype. Neonatology 2012;101:217-24.

12. Sierra H, Sakurai R, Lee WN, Truong NC, Torday JS, Rehan VK. Prenatal rosiglitazone administration to neonatal rat pups does not alter the adult metabolic phenotype. PPAR Res 2012;2012:604216.

13. Rehan VK, Wang Y, Sugano S, et al. In utero nicotine exposure alters fetal rat lung alveolar type II cell proliferation, differentiation, and metabolism. Am J Physiol Lung Cell Mol Physiol 2007;292:L323-33.

14. Komajda M, McMurray JJ, Beck-Nielsen $\mathrm{H}$, et al. Heart failure events with rosiglitazone in type 2 diabetes: data from the RECORD clinical trial. Eur Heart J 2010;31:824-31.

15. Leal I, Romio SA, Schuemie M, Oteri A, Sturkenboom M, Trifirò G. Prescribing pattern of glucose lowering drugs in the United Kingdom in the last decade: a focus on the effects of safety warnings about rosiglitazone. $\mathrm{Br}$ J Clin Pharmacol 2013;75:861-8.
16. Nissen SE, Wolski K. Effect of rosiglitazone on the risk of myocardial infarction and death from cardiovascular causes. N Engl J Med 2007;356: 2457-71.

17. Tolman KG, Freston JW, Kupfer S, Perez A. Liver safety in patients with type 2 diabetes treated with pioglitazone: results from a 3-year, randomized, comparator-controlled study in the US. Drug Saf 2009;32:787-800.

18. Abbas A, Blandon J, Rude J, Elfar A, Mukherjee D. PPAR-? agonist in treatment of diabetes: cardiovascular safety considerations. Cardiovasc Hematol Agents Med Chem 2012;10:124-34.

19. Behrman RE, Butler AS. Preterm Birth: Causes, Consequences, and Prevention. Institute of Medicine (US) Committee on Understanding Premature Birth and Assuring Healthy Outcomes. Washington, DC: National Academies Press, 2007.

20. Crane J, Armson A, Brunner M, et al.; Executive Committee of the Society of Obstetricians and Gynaecologists of Canada. Antenatal corticosteroid therapy for fetal maturation. J Obstet Gynaecol Can 2003;25:45-52.

21. Genovese T, Cuzzocrea S, Di Paola R, et al. Effect of rosiglitazone and 15-deoxy-Delta12,14-prostaglandin J2 on bleomycin-induced lung injury. Eur Respir J 2005;25:225-34.

22. Liu D, Zeng BX, Zhang SH, Yao SL. Rosiglitazone, an agonist of peroxisome proliferator-activated receptor gamma, reduces pulmonary inflammatory response in a rat model of endotoxemia. Inflamm Res 2005;54:464-70.

23. Grommes J, Mörgelin M, Soehnlein O. Pioglitazone attenuates endotoxininduced acute lung injury by reducing neutrophil recruitment. Eur Respir J 2012;40:416-23.

24. Torday JS, Rehan VK. Stretch-stimulated surfactant synthesis is coordinated by the paracrine actions of PTHrP and leptin. Am J Physiol Lung Cell Mol Physiol 2002;283:L130-5.

25. Ferwana M, Firwana B, Hasan R, et al. Pioglitazone and risk of bladder cancer: a meta-analysis of controlled studies. Diabet Med 2013;30:1026-32.

26. Rehan VK, Sakurai R, Li Y, et al. Effects of maternal food restriction on offspring lung extracellular matrix deposition and long term pulmonary function in an experimental rat model. Pediatr Pulmonol 2012;47:162-71. 